Comunicación y género

ISSNe: 2605-1982

https://dx.doi.org/10.5209/cgen.66508

\title{
Devolver la mirada: el personaje de Vera en La piel que habito de Pedro Almodóvar
}

\author{
Michela Russo ${ }^{1}$
}

Resumen. Este ensayo analiza la dialéctica entre mirada masculina y mirada femenina en el cine a través del análisis del personaje de Vera en La piel que habito (2011) de Pedro Almodóvar. El movimiento de la cámara, sus ángulos y tomas materialmente establecen la mirada que estructura una película y construye a sus personajes. Consideramos la noción de mirada masculina desarrollada por Laura Mulvey en 1970, como una mirada que corresponde al placer masculino objetivador. Suplementamos esta noción con la definición de mirada femenina desarrollada por Jill Soloway, como un intento de contrastar esta perspectiva. A través de Vera, que es un personaje transexual, Almodóvar exacerba esta dialéctica entre miradas hasta romperla, a la vez tematizando una noción de feminidad más amplia capaz de instituir una mirada queer.

Palabras clave: emancipación; fluidez; heteronormatividad; mirada; queer; transfeminismo.

\section{[en] Returning the Gaze: The Character of Vera in The Skin I live in by Pedro} Almodóvar

\begin{abstract}
In this essay, the dialectic between male and female gaze in movies is studied through the analysis of the character Vera in Pedro Almodóvar's La piel que habito [The Skin I live in] (2011). The movement of the camera, its angles and takes are what materially establish a gaze and construct characters in films. The notion of male gaze developed by Laura Mulvey in the 1970s is considered, as corresponding to the objectification of female characters for masculine pleasure. This notion is supplemented with Jill Soloway's definition of the female gaze as an attempt to counter this perspective. Through Vera, who is a transsexual character, Almodóvar challenges and breaks this dialectic while thematizing an enlarged notion of femininity capable of establishing a queer gaze.

Keywords: Emancipation; Fluidity; Gaze; Heteronormativity; Queer; Transfeminism.
\end{abstract}

Sumario. 1. Introducción. 2. La mirada masculina y la mirada femenina. 3. La piel que Vera habita: pensar la mirada queer. 4. Conclusiones. Referencias bibliográficas.

Cómo citar: Russo, M. Devolver la mirada: el personaje de Vera en La piel que habito de Pedro Almodóvar. Revista Comunicación y género, 2 (2) 2019, 161-182.

\section{Introducción}

There is a story about two small children

in a museum standing in front of a painting of Adam and Eve.

One child asks the other,

"Which is the man and which is the lady?"

The other child answers,

"I can't tell-they don't have any clothes on". (Judith Shapiro)

1 University of Michigan, Ann Arbor (Estados Unidos) 
El presente trabajo es una lectura de la película de Pedro Almodóvar La piel que habito (2011) desde el cruce entre los estudios de género y sexualidades y el análisis cinematográfico. El análisis de la cámara y de la mirada que esta instituye con sus ángulos y perspectivas constituye una herramienta fundamental para estudiar las dinámicas de género en las películas, en la medida en que la cámara reproduce en el cine lo que podemos llamar el juego o la dialéctica social entre la mirada masculina y la mirada femenina. En particular, considero la película de Almodóvar como una contribución central en el ámbito de la política y de la filosofía tanto queer como feminista, sobre todo con respecto a la perspectiva ofrecida por el transfeminismo (Koyama, 2003).

El transfeminismo defiende el derecho político y social a la expresión de género individualizada y al control del propio cuerpo. En búsqueda de la liberación político-social y discursiva de los cuerpos y, por lo tanto, de mayor justicia, el transfeminismo empieza con teorizar la necesidad de liberación de todas las mujeres junto a la ampliación del concepto mismo de "femenino". Por lo tanto, se moviliza en contra de los mandatos heterosexistas, heteronormativos y patriarcales que reglamentan el sistema de división binaria de género de las sociedades occidentales contemporáneas. Este sistema, a menudo legitimado por las autoridades políticas, médicas y religiosas, normaliza y normativiza según sus propios principios lo que hay que identificar como "genuinamente" femenino y "genuinamente" masculino. En este contexto, sostengo que La piel que habito de Almodóvar ofrece importantes herramientas tanto narrativas como visuales y cinematográficas para desafiar esta ideología heteronormativa, que se expresa en lo que podemos llamar la dialéctica entre mirada masculina y mirada femenina en el cine. En mi trabajo considero esta dialéctica a partir de la definición de mirada masculina desarrollada y popularizada por Laura Mulvey en los años 70 (2009), y de la mirada femenina presentada por la directora y autora de televisión estadounidense Jill Soloway en 2016, en el Toronto International Film Festival. Uso estas dos nociones, además, como herramientas de análisis cinematográfico, y en La piel que habito me enfoco en la construcción del personaje de Vera. Sin embargo, estas nociones reduplican una dialéctica esencialista y heteronormativa que presupone una única y homogénea mirada, tanto femenina como masculina. A este respecto, en mi opinión, la película de Almodóvar articula de una forma contundente un cuestionamiento profundo de las normas de género socialmente compartidas, en tanto que factores fundamentales de la construcción identitaria del sujeto occidental contemporáneo.

La piel que habito, adaptación cinematográfica de la novela negra Tarántula del escritor francés Thierry Jonquet (1984), es un thriller magistral, con una cierta vertiente gótica. Está protagonizada por Antonio Banderas (Doctor Robert Ledgar), Elena Anaya (Vera Cruz), Marisa Paredes (Marilia, la empleada doméstica y madre de Robert), Blanca Suárez (Norma, hija de Robert Ledgard), Jan Cornet (Vicente, chico que trabaja en una tienda de ropa) y Roberto Álamo (Zeca, otro hijo de Marilia). La película tiene lugar en una lujosa mansión en las afueras de la ciudad española de Toledo, El Cigarral, rodeada de olivos y bosques, totalmente aislada del mundo exterior, y escondida de una carretera que pasa por allí cerca. La majestuosidad y la magnificencia de la mansión nos hacen pensar inmediatamente que alguien muy poderoso debe de residir allí. Efectivamente, en El Cigarral vivían, hace un tiempo, el joven e ilustre cirujano Robert Ledgard con su esposa Gal, Norma, su única hija, y Marilia, el ama de llaves. 
La película, sin embargo, se abre con un gran salto temporal, algunos años después, en 2012. Ahora en la mansión viven Robert, Marilia y una extraña y silenciosa figura: Vera, aparentemente una paciente de Robert. La primera secuencia empieza con un plano general de la casa-palacio, que nos ofrece un amplio campo de visión del entorno de la mansión. Rápidamente la cámara se introduce en el interior del edificio, y desde afuera de una ventana vemos la sombra de un cuerpo. Entramos en silencio en el interior de un cuarto. La cámara nos desvela con un primer plano la silueta de un cuerpo femenino, tan bello como sutil, que parece casi andrógino. El cuerpo se encuentra envuelto en una malla del color de la piel, un "body-segunda-piel", así como lo llama Almódovar en su guion, del tipo de los que llevan gimnastas y bailarines, pero que le cubre todo, incluso las extremidades, pies, manos y dedos (Almódovar, 2012: 17). Vemos este cuerpo, que se parece a aquel de una marioneta, extendiéndose y estirándose sobre el reposabrazos de un sofá. Percibimos este cuerpo, que la cámara nos detalla con tanta precisión a través de su lento movimiento, como un cuerpo femenino, y nos recuerda, por un lado, las siluetas de las bailarinas nervudas del artista francés Edgar Degas y, por otro lado, las figuras siniestras, muñecas hechas de gasas y costuras, de la artista feminista franco-americana Louise Bourgeois. Unas pocas secuencias después, y no por casualidad, efectivamente, veremos la cámara encuadrar estas mismas figuras de Bourgeois, que nuestra misteriosa mujer, que más adelante descubriremos que se llama Vera, está construyendo, cortando y pegando entre ellas tiras de su ropa, inspirándose en unos libros de la famosa escultora franco-americana que guarda en su mesa.

No sabemos aún si bajo ese cuerpo andrógino late un corazón humano o mecánico, hasta que, algunas escenas después, vemos escurrir la sangre de sus venas después de haber intentado suicidarse. Poco a poco, a lo largo de la película y entre flashbacks y flash forwards, vamos conociendo más sobre las historias de los tres inquilinos actuales de El Cigarral, Robert, Vera -la única paciente- y Marilia, así como los terribles secretos que allí se ocultan. Efectivamente, lo que esconde El Cigarral es un avanzadísimo salón quirúrgico que en el pasado había sido una clínica de cirugía estética privada y altamente confidencial, donde se practicaban, en secreto, cirugías clandestinas de reasignación de sexo. Sin embargo, este no es el único secreto que se oculta en El Cigarral. En su quirófano, el doctor Robert Ledgard investiga, a partir de experimentos transgénicos, la posibilidad de crear una piel artificial resistente a las quemaduras y a las picaduras de insectos que pueden causar enfermedades graves, como la malaria. Robert llama esta piel GAL, en recuerdo de su esposa, quien se suicidó después de haber sido tremendamente desfigurada por las quemaduras de un accidente automovilístico. Según lo que escribe Vicente Molina Fox en su prólogo al guion de La piel que habito, "la película habla de creadores, de manipuladores, de metteurs en scène que mueven los hilos de la vida de unos individuos tratados como peleles en el escenario de un gran teatro de la mirada" (2012: 8). Sin embargo, no se trata de unos manipuladores y creadores cualesquiera. Sin duda hay muchos niveles de lectura de la cinta, y se puede argumentar, por ejemplo, que la mansión El Cigarral y el personaje de Robert evocan la estructura de los regímenes totalitarios del siglo xx, incluyendo aquel de Franco (Gutiérrez-Albilla, 2018: 141-142). En este ensayo, efectivamente, considero El Cigarral como una alusión al discurso totalitario, pero más específicamente, como una alegoría del discurso de género que estructura el mundo occidental, y de sus imposiciones heteronormativas. 
A partir de aquí, podemos entender la película La piel que habito como un comentario sobre la imposición de las normas que instituyen y regulan el discurso sobre género y la sexualidad en la construcción de los individuos. A la vez, la película, representa y nos habla del encierro social que estas normas conllevan, de la imposibilidad de elegir, la falta de libertad y el drama de quien vive atrapado en un cuerpo o un género que no reconoce o que no siente propio, y con el que, poco a poco, tiene que aprender a convivir. Almodóvar pone en escena, entonces, el drama de vivir en un cuerpo "impuesto" y, así, nos habla también de la lucha profunda entre, por un lado, la mirada que instituye el cuerpo y el discurso masculino y, por otro lado, aquella que instituye el cuerpo y el discurso femenino. Con esta película, Almodóvar cruza las preocupaciones centrales tanto de las teorías queer como de aquellas de las teorías feministas y parece decirnos que no hay ganadores en esta lucha entre miradas. Hay que salir de esta lucha misma deconstruyendo sus mismas condiciones de existencia, es decir, el esencialismo binario de la diferencia sexual y de género en el que solo hay dos opciones: lo masculino y lo femenino. Para adquirir más justicia y equidad social hay que modificar el sistema entero -o marco- de referencia, es decir la "matriz heterosexual", como la llama Judith Butler (2006). Según Butler, habría primariamente que dejar de considerar tanto el género como la sexualidad como identidades y esencialidades fijas, es decir, totalidades inmutables, unificadas y coherentes. Habría que entender tanto el género como la sexualidad en términos de performativos, es decir, como actos, acciones, o cosas que hacemos, sujetas, entonces, a cambios y transformaciones. En este sentido podemos entender el género como una "ficción", una creación y una invención humana. Es decir, como una construcción social y cultural, que corresponde al régimen autocrático, y por lo tanto opresivo, del saber heteronormativo que, con sus discursos de la verdad -para usar una terminología propia del filósofo francés Michel Foucault- moldea a la vez los cuerpos y sus sexualidades, vigilándolos e imponiéndoles sus leyes. Se aprende a habitar el propio cuerpo y el propio género: este parece ser el mensaje de Almodóvar. Pero más allá de este aprendizaje, persiste el cruce, la transición y la fluidez de los cuerpos vivos, al margen de la ley patriarcal. "La norma nos ha dividido. Cortado en dos" -escribe Paul B. Preciado, filósofo y teórico de estudios de género español, en su último libro Un apartamento en Urano- "y forzado después a elegir una de nuestras partes. Lo que denominamos subjetividad no es sino la cicatriz que deja el corte en la multiplicidad de lo que habríamos podido ser" (2019: 23). El personaje de Vera en La piel que habito encarna precisamente, en mi lectura, este cruce que, con sus cicatrices, rompe y deconstruye el orden heteronormativo. Este orden se encuentra representado en la película por la figura de Robert -como veremos, padre creador omnipotente- y reforzado por su contraparte femenina, Marilia, empleada doméstica y madre maldita, generadora culpable de las culpas de sus hijos que, como en un drama griego, constituyen la trama de la película misma. "La culpa es mía" - dice Marilia en un momento de la película-: "tengo la locura en mis entrañas" (min. 38:11).

En el presente trabajo, sin embargo, como he mencionado, analizo la ruptura de este orden heteronormativo encarnada en el cuerpo de Vera no tanto, o no solo, a nivel de la estructura narrativa de la película, sino también a nivel cinematográfico. Considero, efectivamente, cómo el juego de la cámara, vinculado a su vez a las técnicas del montaje y los encuadres cinematográficos, por un lado reproduce y por otro denuncia y rompe, tanto simbólica como materialmente, con el orden binario de las normas heteronormativas. A continuación, en las dos secciones centrales del presen- 
te ensayo, tituladas respectivamente "1. La mirada masculina y la mirada femenina" y "2. La piel que Vera habita", veremos cómo, a través del personaje de Vera, Almodóvar rompe esta dialéctica heteronormativa, a la vez extendiendo el cuadro diseñado por Mulvey y Soloway y vislumbrando la posibilidad de pensar y representar lo que podríamos llamar una mirada queer en el cine.

\section{La mirada masculina y la mirada femenina}

En términos generales, entiendo la noción de mirada como sinónimo de perspectiva, punto de vista o ideología dominante que estructura y significa una narración, sus personajes y las relaciones entre ellos. En una película, la mirada se revela visualmente a través de la manera en que los personajes, los espacios, y los tiempos son representados. La mirada se encarna, por ejemplo, en la manera en que los personajes aparecen en su aspecto físico, su talla, la ropa, el maquillaje, su posición en la escena, o a través de su papel en la narración (por ejemplo, principal o marginal), y sus características étnicas y sociales (clase económica, edad, capacidades físicas, etc.). Pero, de manera más evidente, la mirada se encarna a través del movimiento y del encuadre de la cámara, sus ángulos y perspectivas (por ejemplo, el movimiento de la cámara desde abajo hacia arriba sobre los cuerpos de los personajes, primer plano, zoom-in y zoom-out que se enfocan en partes específicas del cuerpo de los personajes, etc.). El movimiento de la cámara, sus ángulos y tomas, son, en mi lectura, los elementos que materialmente establecen la mirada principal que estructura una película y construye a sus personajes. Por lo tanto, el análisis del movimiento de la cámara representa una herramienta central tanto critico-teórica como educativa para desarrollar competencias de lecturas de las dinámicas, en nuestro caso de género, representadas en las películas. Analizar la trama de una película junto a todos estos elementos mencionados, como el juego de la cámara y los elementos más estrictamente cinematográficos como stage props (escenarios, utilerías, accesorios, indumentarias), los juegos de luces, los sonidos, el montaje, etc., nos ayuda a interpretar más coherentemente cómo se representa -consciente o inconscientemente- la división de género, sus discursos y sus imaginarios en el cine. En este sentido, analizar la mirada de una película a través de estos elementos cinematográficos nos ayuda a interpretar más coherentemente también la manera en que el cine produce, reproduce o desafía concepciones de género y sexualidad, estereotipos, juicios y prejuicios que pertenecen a una determinada sociedad en una cultura y coyuntura histórico-política singular.

De estas consideraciones podemos argüir que, por lo general, todo el cine -incluso aquel que no se define abiertamente como crítico, político o de propaganda- tiene una función social de producción, reproducción o desafío de ideales, comportamientos y modelos para seguir o para contrastar favoreciendo los procesos de identificación entre espectadores y personajes. Podemos decir también que el cine en muchos aspectos representa o refleja, por un lado, los "deseos" de una sociedad y, por otro, sus "miedos". Preguntarse de quién es la mirada dominante que articula una narración o un personaje cuando analizamos una obra -sea literaria, artística o cinematográfica-significa entonces a la vez preguntarse de quién es la voz que escuchamos, quién posee el punto de vista dominante, es decir, quién posee el poder de significar $\mathrm{y}$ darle forma a ese mundo que analizamos, asignando roles y distribuyendo reglas. 
Entender esta mirada, quién habla, a quién pertenece la voz dominante en una narración, significa entonces adquirir la capacidad de analizar con mayor precisión crítica personajes, discursos y mensajes -sean explícitos o implícitos-, llegando incluso a hacer hablar a los silencios, o el inconsciente, de esta misma narración. Un ejemplo de todo esto es la reproducción en el cine de un orden social occidental que corresponde a la ideología patriarcal que ve a la mujer como fundamentalmente pasiva y objeto del deseo masculino. Esta es la perspectiva bajo la cual leo la película La piel que habito, de Pedro Almodóvar.

Mi punto de partida teórico para definir la noción de mirada en estos términos es, como he mencionado, la famosa noción de mirada masculina, desarrollada por la estudiosa del cine y pensadora feminista británica Laura Mulvey en los años 70, en su texto "Visual Pleasure and Narrative Cinema" (2009). En este texto, Mulvey analiza la construcción de los personajes femeninos y masculinos y sus relaciones según la "gramática narrativa" del cine de Hollywood, considerando una variedad de películas entre los años 40 y 70 . Mulvey se da cuenta de que en la mayoría de estas las películas los personajes están construidos por un punto de vista, o mirada dominante, que corresponde al placer o la fantasía masculina. Según lo que escribe Mulvey, la mirada masculina definida por la "gramática narrativa" del cine de Hollywood reproduciría en el cine un orden social patriarcal cuya gramática de división heterosexual de género corresponde precisamente al dictamen del placer masculino. Según esta división, el hombre aparece como el sujeto activo del mirar, y la mujer como fundamentalmente pasiva e hipersexualizada, objeto de este mirar placentero (escopofilia la llama Mulvey, usando un término psicoanalítico), que corresponde al deseo masculino. El acto de mirar aparece entonces aquí como fuente unidireccional de placer que se transforma en una narrativa cinematográfica dominada por la ideología patriarcal. Esta gramática visual reproduce una diferencia de género que, recreando a su vez una fantasía de omnipotencia masculina ya descrita por el psicoanálisis freudiano, según Mulvey pone al hombre (tanto personaje como espectador) en una posición de poder. Esto sucede porque la figura masculina en la gramática heteronormativa patriarcal ocupa la posición activa del sujeto de la mirada, objetificando y cosificando el cuerpo del personaje femenino, o incluso del personaje masculino, representando por tanto una misma división heteronormativa en narraciones que en principio no son heteronormativas. En este sentido, el análisis de Mulvey se desarrolla a partir del desarme de un malentendido capital: el mirar nunca es un acto pasivo; nosotros, espectadores, no asistimos pasivos al curso de la acción de los personajes en la pantalla que está en frente a nuestros ojos. Por el contrario, el acto de mirar, por el hecho de ser acto, o sea, acción, corresponde en la visión de Mulvey a un momento activo de posesión y, a la vez, de construcción del objeto de la mirada, que en este caso corresponde al cuerpo femenino, el cual, por el hecho mismo de ser objeto de la mirada, se encuentra objetificado, cosificado y pasivo. Un cuerpo cuyo destino y valor en la narración depende enteramente del sujeto de la acción masculino. Como veremos más adelante, Robert Ledgard, el médico cirujano protagonista de la película La piel que habito de Almodóvar, encarna perfectamente esta mirada, entre creación y vigilancia. Su ojo masculino, deseante y disciplinante, policial y médico, al mismo tiempo padre y amante, literalmente construye el cuerpo femenino de Vera. A través de su ojo masculino, de la vigilancia de su cámara unidireccional -como un panóptico en la terminología de Michel Foucault (2018)-, y del saber sobre las normas sociales de género, que es al mismo tiempo el saber mayúsculo y 
científico, y el saber minúsculo del sentido común. Robert le enseña a Vera a habitar su propio cuerpo en el aislamiento de su celda, a cómo identificarse con una mujer y a cómo devenir mujer (Deleuze y Guattari, 2002). El personaje de Robert nos habla, a través de estas dinámicas narrativas, de la contingencia y arbitrariedad, a la vez que del desequilibrio de las normas sociales de identificación estética y de comportamiento que definen y construyen el género.

A partir de estas consideraciones, nos preguntamos por la posibilidad de teorizar la noción de mirada femenina en el cine como un intento de contrarrestar esta perspectiva masculina objetivadora y dominante descrita por Mulvey, a la vez preguntándonos por la posibilidad de pensar tanto la masculinidad como la feminidad en otros términos. La mirada femenina en el cine, por lo tanto, no sería una mera inversión del punto de vista dominante masculino en una película, y entonces una objetificación del cuerpo masculino, sino una herramienta de emancipación, que intentaría romper con esta perniciosa dialéctica ente masculino-activo y femenino-pasivo a través de la transformación del personaje femenino en sujeto activo. Entendida como herramienta de emancipación, entonces, la mirada femenina correspondería a una mirada en el cine que intenta devolver a los personajes femeninos su subjetividad, representándolos como personajes complejos, con capacidad de acción y potencial decisional. En otras palabras, la mirada femenina sería la que intenta restituir una cierta "agencia" a los personajes femeninos, así representándolos ya no como entorno u objetos pasivos de placer, sino como sujetos de sus propias narraciones, es decir, tanto sujetos de sus destinos como de sus deseos.

Intentando formalizar un acercamiento teórico para definir este cambio de mirada, en este artículo suplementamos la teorización de Laura Mulvey con la definición de mirada femenina delineada por la creadora televisiva estadounidense Jill Soloway, famosa por la serie de televisión Transparent, tal como la presentó en una charla magistral pronunciada en 2016 en el Toronto International Film Festival (TIFF). En esta charla, Soloway identifica tres aspectos o técnicas cinematográficas que construyen la mirada femenina en una película. Primero, el "sentir mirando" [feeling seeing] construido por la cámara subjetiva que nos sitúa desde el punto de vista del personaje femenino y nos hace percibir lo que ella percibe. Aquí el personaje femenino no es mero objeto de la mirada, adquiere una cierta independencia en la narración y subjetividad en la acción, percibimos su subjetividad porque percibimos sus sentimientos, su deseo está representado, será un personaje más complejo y desarrollado. Segundo, "el sentirse mirado" -o la "mirada mirada" [the gazed gaze]-, es decir el sentimiento restituido por la cámara de estar siendo mirada por alguien. El personaje se da cuenta de que es mirado, es decir-fuera de la metáfora- el personaje toma consciencia de sí mismo, de sus condiciones de dependencia y subordinación, y finalmente de su objetificación. El sentimiento de estar siendo objeto de la mirada corresponde a un momento central de autoconsciencia. La toma de consciencia de los seres humanos de estar siendo mirados corresponde a la toma de consciencia de estar siendo objetificados por el ojo de alguien. Esta toma de conciencia de las propias condiciones de existencia -o de "opresión", como sería más apropiado decir en este contexto-, es el primer paso para la realización de cualquier acto o movimiento emancipatorio. En términos de técnicas cinematográficas y de narración, esto se traduciría en la representación de un personaje que se descubre a sí mismo y que adquiere autoconsciencia sobre los discursos y los mecanismos sociales que construyen a su ser. En este caso, sería la representación de la toma de conciencia 
de un ser femenino con respecto a su construcción como un sujeto pasivo, débil, con poca agencia, impotente o al cual, en la narración, se le impide ser responsable de su propio destino, tanto en términos particulares - por ejemplo es incapaz de tomar una decisión fuerte e ir a contracorriente-, como en términos narrativos generales, por ejemplo mantiene un papel secundario y no logra convertirse en héroe o personaje principal de la historia. El tercer y último aspecto que según Soloway caracteriza la mirada femenina es la posibilidad de "devolver la mirada" [returning the gaze], tanto literalmente a través del juego de la cámara, como metafóricamente. A este respecto, el personaje femenino no solo toma consciencia, sino que también ejecuta la acción y se convierte finalmente en sujeto dueño de su propio destino en la película, por ejemplo, se rebela o rechaza sus anteriores condiciones de dominación. De esta forma, el personaje femenino se emancipa en su narración. No solo toma consciencia de sus condiciones de existencia, sino que con un acto de rebeldía también devuelve -literalmente- la mirada, transformándose en sujeto activo tanto de la visión como de la trama de una película. Nosotros, como espectadores, miraremos y sentiremos a través de sus propios ojos.

En mi lectura de la película de La piel que habito, de Almodóvar, el personaje de Vera, que protagoniza la película, es portadora de esta "mirada femenina" porque tanto la cámara como la narración reproducen estos tres aspectos descritos por Soloway, como respuesta a la mirada masculina encarnada en el personaje de Robert. A este respecto, mi análisis se enfoca en el juego entre la mirada médica, policial y controladora de Robert, el doctor que literalmente crea y resignifica el cuerpo de Vera practicando una no querida operación de reasignación de sexo, y la mirada que Vera devuelve a través de la cámara unidireccional que la controla en el aislamiento de su cuarto-celda. Sin embargo, este juego entre mirada masculina y femenina reproduce implícitamente esta misma división heterosexual de género que atrapa a los personajes en un binarismo que limita y enclaustra la creación misma de los personajes en el discurso cinematográfico. Esta clausura binaria de la película corresponde, obviamente, a una clausura real en el discurso patriarcal que articula el mundo donde vivimos, y donde cada individuo se encuentra obligado a ocupar posiciones, identidades y roles de géneros fijos, predefinidos y naturalizados por las ideologías dominantes. En otras palabras, la idea de mirada femenina como respuesta emancipadora al discurso objetificante de la mirada masculina no haría otra cosa que seguir jugando con las mismas reglas del discurso heteronormativo patriarcal, en lugar de desafiarlo o deconstruirlo, terminando por reproducirlo y reforzarlo indirectamente en el momento preciso en que se construye dialécticamente como su oposición. A este respecto, la película La piel que habito de Almodóvar introduce una ruptura fundamental: después de reproducir esta dialéctica conflictiva entre mirada masculina y mirada femenina, la película tematiza, hacia el final, precisamente su disolución a través del mismo personaje de Vera, que es un personaje transexual.

\section{La piel que Vera habita: pensar la mirada queer}

La piel que habito empieza presentándonos al personaje de Vera, encerrada en su habitación en el interior de la casa-palacio de El Cigarral. Almodóvar así describe así a Vera: 
Bajo el body-segunda-piel palpita el cuerpo de Vera. No es muy alta, pero posee un cuerpo proporcionado y fibroso. Aparenta unos veinticinco años, la figura delgada, la piel del rostro tersa y suave, casi brillante, el pelo oscuro, a la altura de los hombros, recogido casualmente. Ejecuta algunas posturas de yoga, aunque en el principio dé la impresión de ser una muñeca abandonada en un desván limpio y aséptico [...]. (Almodóvar, 2012: 17-18)

Efectivamente, la habitación de Vera, que se encuentra en la segunda planta de la mansión El Cigarral, es un amplio cuarto, diáfano y austero. Los únicos muebles son una cama, un sofá, una mesita y un armario tipo clóset. También hay en el cuarto unas barras de danza y unas bolas de diferentes dimensiones para hacer ejercicio físico, un espejo a la altura del rostro, una televisión de plasma, unos libros y unas muñecas de tamaños diversos que Vera confecciona inspirándose en la obra de la artista franco-americana Louise Bourgeois. Las paredes del cuarto se encuentran cubiertas por escritos, grafismos varios y dibujos, así como unas fechas, 2006-2012, que suponemos indican el tiempo transcurrido para Vera en ese lugar. El único contacto con el mundo de afuera pasa por dos ventanitas altas con rejas -desde las cuales solo se pueden ver árboles y un trozo de cielo- y un interfono -a través del cual Vera puede comunicarse con los otros dos inquilinos de la mansión, Marilia y Robert-. Además, se encuentran en el cuarto una pequeña puerta metálica, una especie de ascensor montaplatos por donde Marilia manda la comida a Vera y, finalmente, unas cámaras unidireccionales de control interno que observan, desde diferentes ángulos, la totalidad de la habitación de Vera. A través de estas cámaras, Vera puede ser constantemente mirada y vigilada sin poder, a su vez, mirar nada de lo que pasa afuera.

La segunda secuencia con la cual empieza La piel que habito nos presenta el personaje del doctor Robert Ledgard que, desde un púlpito puesto en el centro en un salón del Colegio de Médicos, está dando una charla sobre trasplantes de rostros para las víctimas de incendios. En las secuencias sucesivas vemos a Robert en otros tres lugares que lo definen como personaje. Primero, lo vemos en su laboratorio médico, en los subterráneos de El Cigarral, que cuenta con la más avanzada tecnología médica. En el laboratorio se encuentran numerosas herramientas quirúrgicas, computadoras y pantallas que muestran diferentes partes del cuerpo humano, especialmente genitales masculinos y femeninos; vemos terrarios con insectos, cultivos de piel artificial y un maniquí humano de tamaño natural tumbado sobre una mesa de operaciones. Luego, vemos a Robert entrar en su propia habitación, llena de obras de arte famosas, un poco barroca y oscura, con una gran pantalla de plasma en el centro desde la cual contempla absorto las curvas perfectas del cuerpo de Vera, que yace de espalda. Finalmente, vemos a Robert como personaje público, dando una charla magistral en el instituto de biotecnología acerca de su mayor descubrimiento científico, la piel artificial GAL. Nos encontramos, aquí, en un auditórium circular con las paredes cubiertas con estanterías con libros, y vemos a Robert ante un claustro de eminentes cirujanos, predominantemente masculinos. Esta escena austera es muy interesante, porque establece de forma clara la voz más poderosa y dominante de la película, que es la voz de la autoridad científica, una autoridad, nuevamente, predominantemente masculina. En unos fotogramas sucesivos, durante el banquete, escuchamos fragmentos de una conversación privada con el presidente del Instituto de Biotecnología. Robert admite que su descubri- 
miento es el resultado de unos experimentos de transgénesis con células humanas, generando en el presidente ásperas reacciones de desaprobación en nombre de la bioética.

Estas primeras secuencias son muy importantes porque encuadran inmediatamente a la figura de Robert. Retratan claramente a Robert según los tropos centrales en la narración gótica del cine de terror en blanco y negro. No es un secreto, por ejemplo, que otra fuente de inspiración para la realización de La piel que habito es la película franco-italiana Los ojos sin rostro dirigida por Georges Franju (1960). El protagonista de esta película, el doctor Génessier, es un cirujano plástico que va raptando a mujeres con el fin de efectuar un trasplante de rostro a su hija, terriblemente desfigurada después de un accidente automovilístico. De manera parecida, Robert, en la película de Almodóvar, encarna el científico loco con sus fantasías de omnipotencia. Esta figura, podemos agregar incluso, está inspirada en numerosos personajes en la historia del cine occidental, desde el Doctor Jekyll y Caligari, a Frankestein y Mabuse. En La piel que habito, además, tampoco faltan elementos gore, típicos del cine de terror. También hay personajes grotescos, como Zeca -el hermanastro de Robert-, cuyo apodo es Tigre, y que aparece apropiadamente disfrazado con vestuario de felino. No falta tampoco la figura de la gobernanta maléfica, encarnada en la figura de Marilia, una mujer ya mayor, con rasgos a menudo crueles, y atenazada de sufrimiento y añoranza (Molina Fox, en Almodóvar, 2012: 7-12). Sin embargo, lo que Robert planea y ejecuta en su mansión en el curso de seis años no es nada más que un plan de venganza, que una vez más se inscribe perfectamente en la fantasía de omnipotencia que lo caracteriza, construyéndolo como figura soberana, casi divina, a la vez creadora absoluta y castigadora, que se arroga el poder de dar la vida y provocar la muerte.

Tras la introducción de la figura de Robert, el montaje con unos flashbacks nos permite enterarnos de lo que había pasado unos seis años atrás. Estos flashbacks parecen corresponder a la memoria de Vera, los cuales toman forma a partir de sus sueños, en un momento en que se encuentra dormida con Robert. Los dos -escribe Almodóvar- "duermen, con los cuerpos enredados y las cabezas juntas. Podrían transmitirse los sueños el uno al otro" (2012: 76). Así empieza el flashback. Seis años antes, durante una fiesta en la cual Robert participa con su hija adolescente, Norma -de dieciocho años, un poco desubicada y que sufre algún tipo de trastorno nervioso (2012: 77)-, ocurre una segunda tragedia en la vida de Robert-recordemos que la primera fue el suicidio de su esposa Gal-, la cual provoca un viraje repentino en sus investigaciones científicas. Norma, ya profundamente traumatizada por haber vivido de niña el suicidio de su madre, durante la fiesta es violada por un chico que apenas ha conocido, Vicente, quien trabaja en una tienda de ropa de mujeres con su mamá. Norma, encerrada en una clínica psiquiátrica después del accidente, no supera este segundo trauma, y después de poco tiempo se suicida, tal y como hizo su madre. Robert, profundamente alterado, planea venganza. Rapta a Vicente y, como castigo, lo narcotiza y lo somete, anestesiado, a una no querida cirugía de reasignación de sexo. La operación tiene éxito. Robert encierra a Vicente en su casa, en un cuarto-celda, rodeado de cámaras de vigilancia unidireccional que lo vigilan desde diferentes ángulos, $\mathrm{y}$, después del abrupto cambio de sexo, lentamente le obliga a devenir mujer. Robert se transforma entonces en una figura omnipotente, Deus ex machina, dueño del poder soberano divino de castigar y decidir sobre la vida y la muerte, que literalmente genera y construye, 
nombrándolo, su objeto de deseo: Vera Cruz, sobre el cual -o la cual- puede ejercer un poder infinito. Poseedor de un saber poderoso, científico -que, por lo tanto, se identifica con lo masculino-, Robert, como he mencionado, le enseña a Vera cómo habitar su nuevo cuerpo, su cuerpo de mujer, y entonces le enseña cómo devenir mujer.

Es importante subrayar este aspecto porque el poseedor del saber acerca de lo femenino, sobre qué es una mujer, no es ni Marilia, la anciana ama de llaves, ni ninguna otra figura femenina en la película. Por el contrario, es Robert, es decir, su mirada masculina, que literalmente produce el objeto de $s u$ mirada y todo el conocimiento necesario sobre este según su deseo. Es muy significativo, y casi irónico, que la nueva mujer, creación de Robert, se llame "Vera". La etimología del nombre Vera, efectivamente, alude a la palabra "verdadera", sugiriéndonos así que la "verdadera mujer", lo que es "verdaderamente femenino", no es nada más que una construcción y un invento. Almodóvar parece aquí hacer eco, invirtiéndolo, del famoso monólogo de Agrado en su película anterior Todo sobre mi madre (1999): "Además de agradable, soy muy auténtica”, dice Agrado, “...cuesta mucho ser auténtica, señora, y en estas cosas no hay que ser rácana, porque una es más auténtica cuanto más se parece a lo que ha soñado de sí misma”. La autenticidad, otra vez, no es ningún dato natural, es una fidelidad a un modelo que es pura creación e invención. De forma parecida, el artista estadounidense Andy Warhol ya en los años 60 se refería al transexualismo y al transgenerismo masculino como una forma de deconstrucción de la naturalización y del esencialismo de género, y del futurismo reproductivo, describiendo a las mujeres trans como "archivos ambulantes de la femineidad ideal" capaces de construir estéticamente la "verdadera identidad femenina" (Mecacci, 2008: 71-76, traducción propia). Sin embargo, frente al saber poderoso y masculino de Robert, desde la primera escena de la película, podemos notar cómo silenciosamente Vera está construyendo otro entramado, otro discurso que le permitirá precisamente emanciparse como personaje. Me refiero a los modelos de muñecas inspirados en la obra de la artista Louise Bourgeois que Vera va construyendo con fragmentos de sus propios vestidos de mujer, que, muy significativamente, va rasgando y destrozando poco a poco. Muy significativamente, porque la ropa es lo que principalmente define nuestra identidad de género, precisamente como una segunda piel (Laine, 2014: 4). Vera lee, estudia y aprende de los libros el trabajo feminista de Louise Burgeois y, por lo tanto, podemos decir que interioriza y reproduce su obra. De esta forma, en mi lectura, Vera está construyendo y dando vida a un contra-saber, un saber alternativo con respecto al régimen autocrático del saber científico y heteronormativo representado por la figura de Robert.

Efectivamente, toda la obra artística de Bourgeois, que es predominantemente escultórica, no es otra cosa que una forma de resistencia a los patrones genealógicos y esencialistas impuestos por la ideología patriarcal, con referencia explícita a temas como violencia y deseo (Nixon 2005). Por ejemplo, muchas de las obras de Bourgeois son figuras primitivistas, algunas de estas forman la serie "mujeres fálicas", lo cual sugiere, según la crítica de arte Patricia Mayayo, la "intercambiabilidad de los roles sexuales, la posibilidad de que el sujeto adopte en determinado momento una posición masculina o femenina, sea cual sea su sexo biológico" (Mayayo, 2002: 33 citado en Cabello Ruiz, 2014: 42). Además, otras obras de Bourgeois tratan el tema de la histeria y la enfermedad mental femenina, que en la historia del psicoanálisis ha llegado a representar indistintamente tanto enferme- 
dades físicas como formas de trastornos psicológicos, o de pura "rebeldía" femenina. Vera se encuentra encerrada precisamente como una histérica, y sus posturas, estirándose y haciendo yoga, recuerdan y recrean estas imágenes de Bougeois, en particular una, llamada "Arch of histeria" (1993), que traza la curvatura extrema de un cuerpo dolorido por espasmos (Cabello Ruiz, 2014: 43; Jung, 2014: 624630). Considero entonces el momento de auto-aprendizaje y reproducción de un contra-saber práctico y de resistencia por parte de Vera como el momento de construcción de una autoconsciencia, que según Soloway es uno de los aspectos que caracteriza la mirada femenina. Este momento de autoconsciencia, además, es aún más complejo en la medida en que Vera se encuentra atrapada por la violencia del discurso patriarcal como mujer -sujeta a la violencia de quién desea su cuerpo-y también como hombre, que había sido, en el pasado, el perpetrador de esa misma violencia. En efecto, y con una muy amarga ironía de la suerte típica del melodrama almodovariano, Vera experimenta, por mano de Zeca y también de Robert, la misma violencia que había a su vez ejercido, seis años atrás, cuando aún era Vicente, sobre el cuerpo de Norma, la hija de Robert. El momento de autoconsciencia del personaje de Vera, entonces, en mi lectura, alude una vez más al hecho de que la deconstrucción de la máquina poderosa del discurso heteronormativo patriarcal significa, al mismo tiempo, poner en cuestión y desquiciar tanto la categoría de lo masculino como la de lo femenino.

A partir de todas estas consideraciones analizo en detalle, en las páginas que siguen, tres escenas de esta importante y controvertida película de Almodóvar en que aparecen claramente, a través de sus respectivas técnicas cinematográficas, los siguientes puntos:

- La reproducción, por los personajes de Robert y Vera, de la dialéctica entre la mirada masculina y la mirada femenina, según las técnicas descritas por Mulvey y Soloway, a través de la estrategia narrativa de la cámara unidireccional.

- La reproducción de la complejidad de la mirada masculina según como aparece en el análisis de Mulvey, y encarnada en el personaje de Robert; una mirada que es a la vez creadora, deseante y vigilante (en sentido tanto médico como policial), y que se encuentra reproducida tanto a través del dispositivo narrativo de la cámara unidireccional como del uso indiscreto del plano cenital que se introduce en la intimidad de los momentos privados de Vera.

- La ruptura de la dialéctica heteronormativa entre mirada masculina y mirada femenina -que reproduce la división entre lo masculino, activo y sujeto de la mirada, y lo femenino, pasivo objeto de la mirada-, encarnada en el personaje de Vera y construida cinematográficamente por un dramático plano cenital al final de la película.

La primera escena sobre la que quiero profundizar se encuentra en la secuencia número 31, en la habitación del Doctor Ledgard, interior noche (Almodóvar, 2012: 38). Desde mi lectura, considero que esta escena representa magistralmente la dialéctica entre el deseo de dominación de la mirada masculina y el deseo de emancipación de la mirada femenina. 


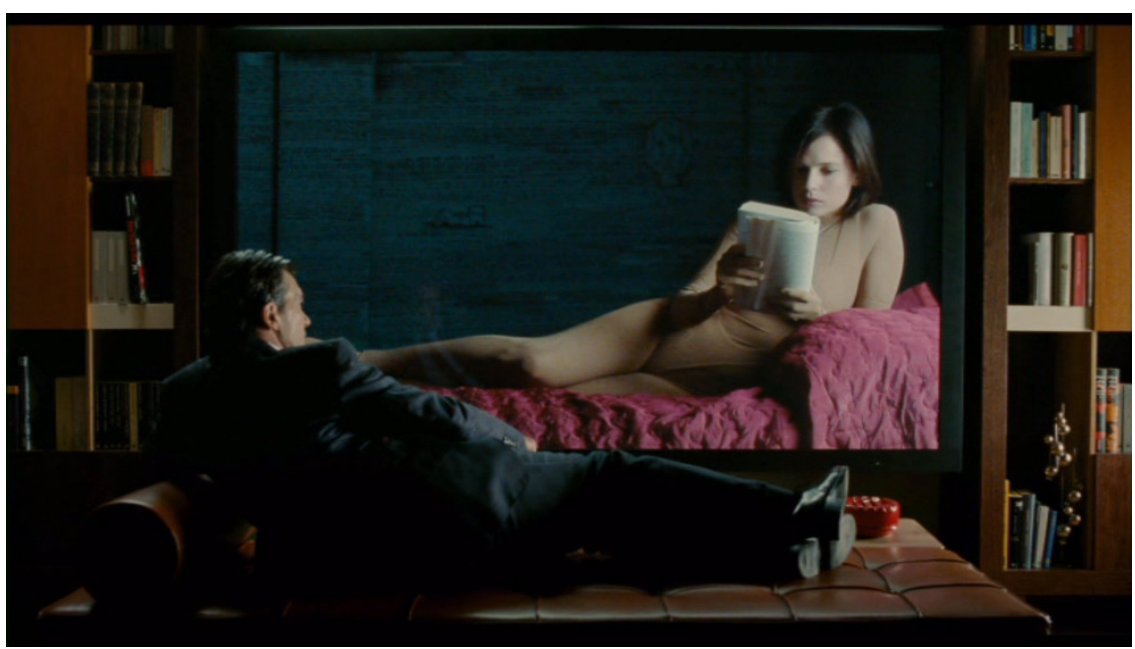

Figura 1. La piel que habito: Robert mira a Vera en su pantalla

En la escena, Robert vuelve a su cuarto después de su charla en el Instituto de Biotecnología. Como de costumbre, toma el control remoto, prende la pantalla de plasma, y se tumba de lado, espectador frente a su espectáculo (figuras 1 y 2). Lo que mira en la pantalla, sin embargo, no es una película, sino el cuerpo -inconsciente de estar siendo mirado, o así al menos pensamos nosotros- de Vera, quien está absorta en la lectura de un libro. Robert la observa con una mirada entre vigilante y deseante, el objeto literal de su creación, Vera, la cual encarna su ideal de perfección femenina. Esta escena recrea literalmente la dinámica que Mulvey describe a nivel simbólico, a partir del espectador masculino en las películas de Hollywood -el sujeto activo de la mirada- que crea y significa, cosificando e hipersexualizando, el objeto de su mirada, es decir, el cuerpo femenino, objeto pasivo del espectáculo. La recrea literalmente porque Robert es el creador del cuerpo de Vera según sus deseos, que en esta escena es específicamente espectáculo en la pantalla: la vigila, la observa, y claramente la desea a través de la cámara unidireccional de control interno. Vera, desde el aislamiento de su cuarto-celda, aparentemente ignora el hecho de estar siendo mirada. Vera está tumbada pasiva como en una pintura, su figura evoca tanto a la Maja desnuda de Francisco de Goya (1797-1800) como a la Venus del espejo de Velázquez (1599-1660). Efectivamente, vemos la casa de Robert completamente adornada de telas de artistas celebres, la mayoría de las cuales retratan a Venus, diosa de la belleza en la mitología romana que, una vez más, dicta y ordena el canon y las normas de belleza sobre el cuerpo femenino. Entre las reproducciones de Venus vemos, por ejemplo, colgadas en las paredes de la mansión, las telas de Tiziano: la Venus de Urbino (1538) y la Venus recreándose en la música (1550). La figura de Vera tumbada así, como aparece en la pantalla del cuarto de Robert, evoca precisamente esta serie de imágenes (Jung, 2014: 619-624; Parés Pulido, 2014: 341-349; Thibaudeau, 2013: 201-202).

La mujer y su cuerpo aparecen, entonces, en esta multiplicación de imágenes y pinturas, nada más que como un objeto de creación artística para ser mirado (Laine, 2014: 2) y como un espectáculo sin profundidad. La misma Vera, al final de esta escena, le pregunta a Robert, una vez ha entrado en el cuarto-celda: "¿Te gusta lo que 
ves? [...] Entonces, ¿puedo darme por terminada?” (Almodóvar, 2012: 39). A este respecto, Vera aparece, en la escena de la pantalla, como un personaje sin complejidad; no sabemos nada de ella, no conocemos sus pensamientos y sentimientos, ni tampoco su historia. Apenas en unas secuencias anteriores descubrimos que sí hay un corazón que late bajo el bodi del color de la piel, y lo descubrimos por la carne viva de su cuerpo, y la sangre que se escurre después de haber intentado suicidarse. Sin embargo, de repente hay un giro inesperado en la escena. Vera parece de repente tomar consciencia de estar siendo mirada. Distraída, deja de mirar el libro y, tras la sorpresa de Robert, devuelve la mirada y lo mira fijamente a los ojos. Simultáneamente, la cámara hace zum sobre la cara de Vera, ahora gigante, cuyo tamaño en perspectiva es más del doble de la cara de Robert. Vera no puede estar viendo a Robert, porque se trata de una cámara de control unidireccional, y, sin embargo, tomando conciencia de estar siendo cosificada, devuelve la mirada. El zum en su cara no hace sino reforzar visualmente el empoderamiento que esta mirada representa. Ahora Robert es pequeño, ya una hormiga en frente de su cautivador rostro. Ahora la mirada es recíproca, Vera empieza a empoderarse y a emanciparse como personaje (figura 3).
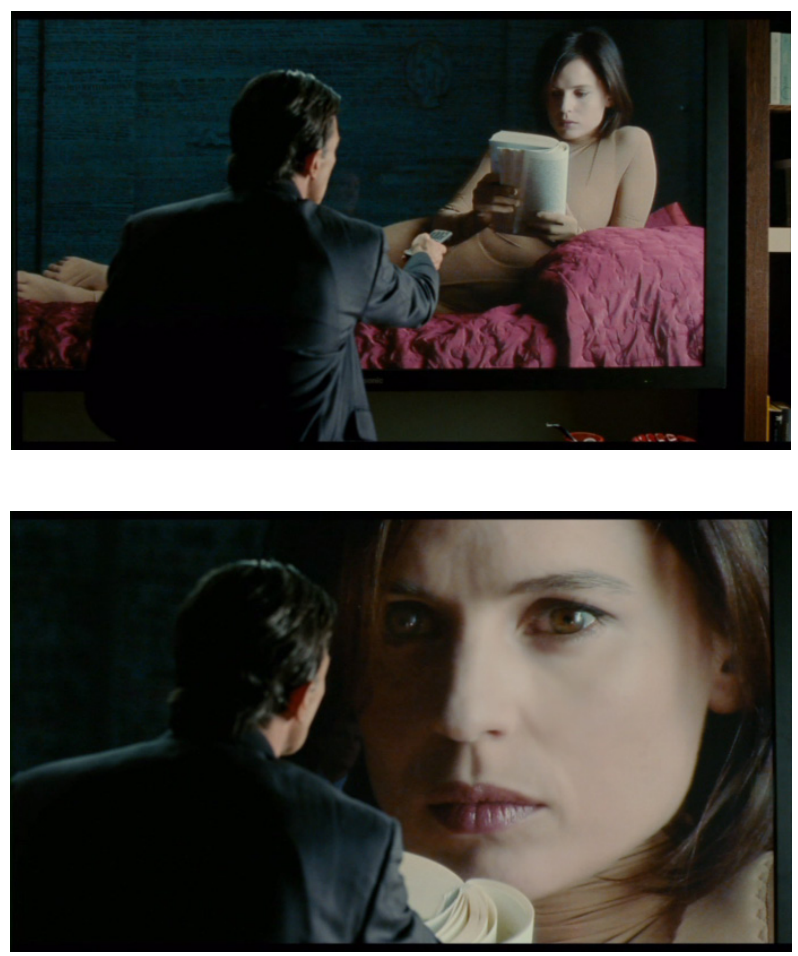

Figuras 2 y 3. La piel que habito: Robert con el control remoto; Vera devuelve la mirada

Este giro repentino rompe la gramática unidireccional entre sujeto activo y objeto pasivo de la mirada masculina y representa, desde mi punto de vista, la construcción cinematográfica de la mirada femenina como una herramienta emancipadora de acuerdo a cómo es descrita por Soloway. Efectivamente, de aquí en adelante 
Vera empezará a planear su huida de El Cigarral y, por lo tanto, su emancipación como personaje en la narración misma. De aquí, quiero detallar la manera en que se encuentra representada cinematográficamente la mirada masculina entre creación y vigilancia. Una manera es, obviamente, la que acabo de describir: la estrategia narrativa de la cámara de vigilancia interna unidireccional recrea perfectamente esta sensación de cosificación y espectacularización del cuerpo femenino. Asimismo, en esta secuencia vemos a Robert manejar un control remoto, un gesto que, sugerentemente, enfatiza su ser espectador masculino y posesor activo de la mirada. Este mismo desequilibrio se repite en algunas secuencias después, con la llegada a El Cigarral de Zeca, hijo secreto de Marilia y examante de Gal, la esposa de Robert. Zeca confunde a Vera con Gal, y con violencia la saca de su celda para violarla. Además de tematizar sutilmente la intercambiabilidad del cuerpo-objeto femenino, estas secuencias reduplican la cosificación del cuerpo femenino a través de una equivalencia entre el objeto del deseo y el objeto inanimado de posesión, donde precisamente el consenso no es necesario (figura 4).

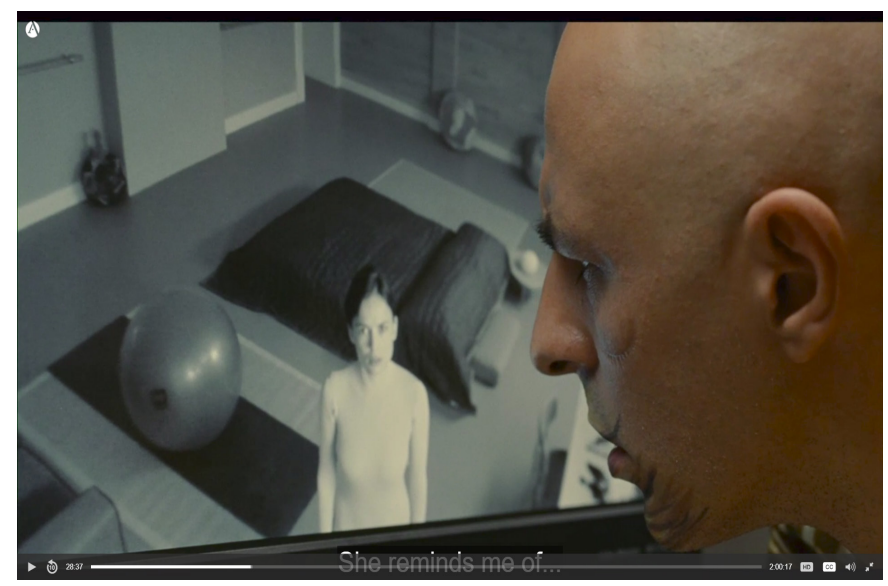

Figura 4. La piel que habito: Zeca mirando a Vera de la pantalla de control interno

Además del uso de la cámara unidireccional como técnica narrativa para recrear la sensación de objetificación del cuerpo femenino, quiero subrayar la importancia cinematográfica del uso del plano cenital en algunas secuencias en flashbacks, que nos muestran el proceso de transición de Vicente a Vera en los seis años de reclusión en la mansión de El Cigarral. Ambos, la cámara de vigilancia interna y el plano cenital, tienen como efecto la recreación de un espacio de cautiverio que recuerda el panóptico, el modelo de prisión descrito por el filósofo francés Michel Foucault en su texto Vigilar y Castigar (2018). El panóptico es un modelo de arquitectura carcelaria ideada por el filósofo Jeremy Bentham hacia finales del siglo XVIII, de forma circular y con una torre de control puesta en el centro. Los encarcelados se encuentran aislados y literalmente observados constantemente, objetos de una mirada que no pueden devolver, y presos de un sistema cuyo objetivo es de vigilar, disciplinar, y gobernar. Lo mismo podemos decir del sistema de cámaras que permiten la mirada unidireccional en el cuarto-celda de Vera. El ojo médico y policial de Robert es lo que vigila, disciplina y gobierna 
constantemente el cuerpo de Vera. Además, como ya he mencionado, Robert es también dueño del saber, posesor de todos los conocimientos necesarios que definen la femineidad perfecta e ideal, y con esta autoridad le enseña a Vicente-Vera a devenir mujer. A este respecto, el plano cenital del cinematógrafo omnisciente refuerza la mirada panóptica de Robert, en la medida en que indiscretamente nos hace observar y vigilar también a nosotros, espectadores, los momentos más íntimos de la transición de Vera.

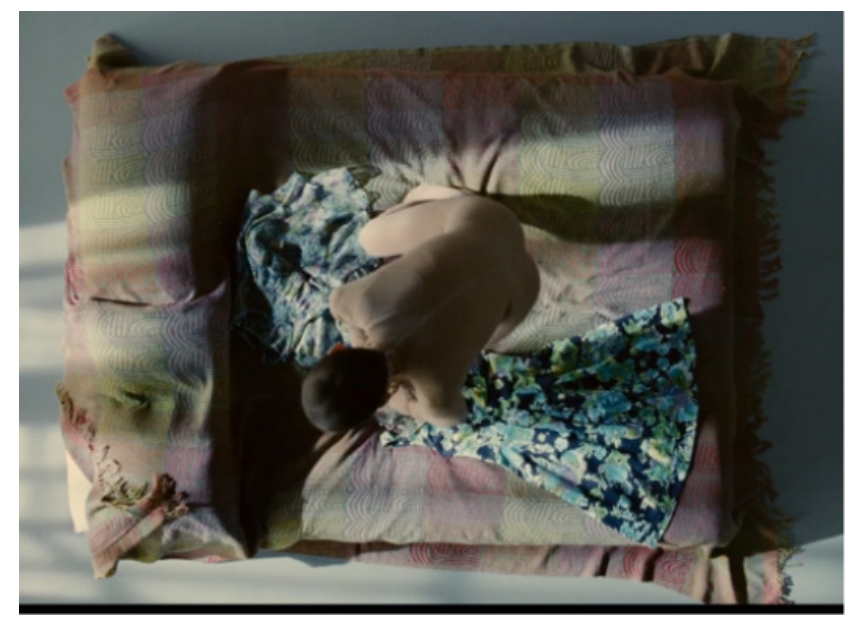

Figura 5. La piel que habito: Plano cenital de Vera destruyendo a sus vestidos

En el fotograma desde arriba (figura 5), la cámara se corresponde con el ojo del creador omnipresente y omnisciente, que no pertenece a ningún personaje en particular, y que por lo tanto nos aparece asfixiante, oprimente e indiscreto, un creador que controla minuciosamente la intimidad de la protagonista, mostrándonos lo que normalmente no se muestra al ojo curioso, en su proceso de devenir mujer. Aquí vemos a Vera obligada a maquillarse y a ponerse ropa estereotipadamente femenina, como vestidos floreados, siendo así doblemente atrapada: en la celda y en un cuerpo que no reconoce como propio, haciéndonos percibir -al revés- la sensación de quien nace sintiéndose atrapado en un cuerpo y una identidad que no se reconocen como propios o adecuados. Vera tiene primero que aprender a "habitar" el propio cuerpo para poder romper el orden que la modela. Esta ruptura es precisamente lo que pasa al final de la película, que corresponde a la liberación y emancipación del personaje de Vera de su doble cautiverio, tanto en la mansión de Robert como de las prescripciones de género impuestas en su cuerpo, un cuerpo en que ahora coexisten, sobreponiéndose, tanto la mirada masculina como la mirada femenina. El personaje de Vera, entonces, efectúa la ruptura del orden patriarcal mismo, matando a Robert y Marilia, tropos respectivamente de la figura paterna y materna según el humanismo occidental. Con el orden patriarcal, Vera destruye también el mito del complejo de Edipo, que podemos considerar entre una de las instituciones centrales que también estructuran y significan la división de género en el pensamiento occidental a través de los siglos y cruzando varias disciplinas. 


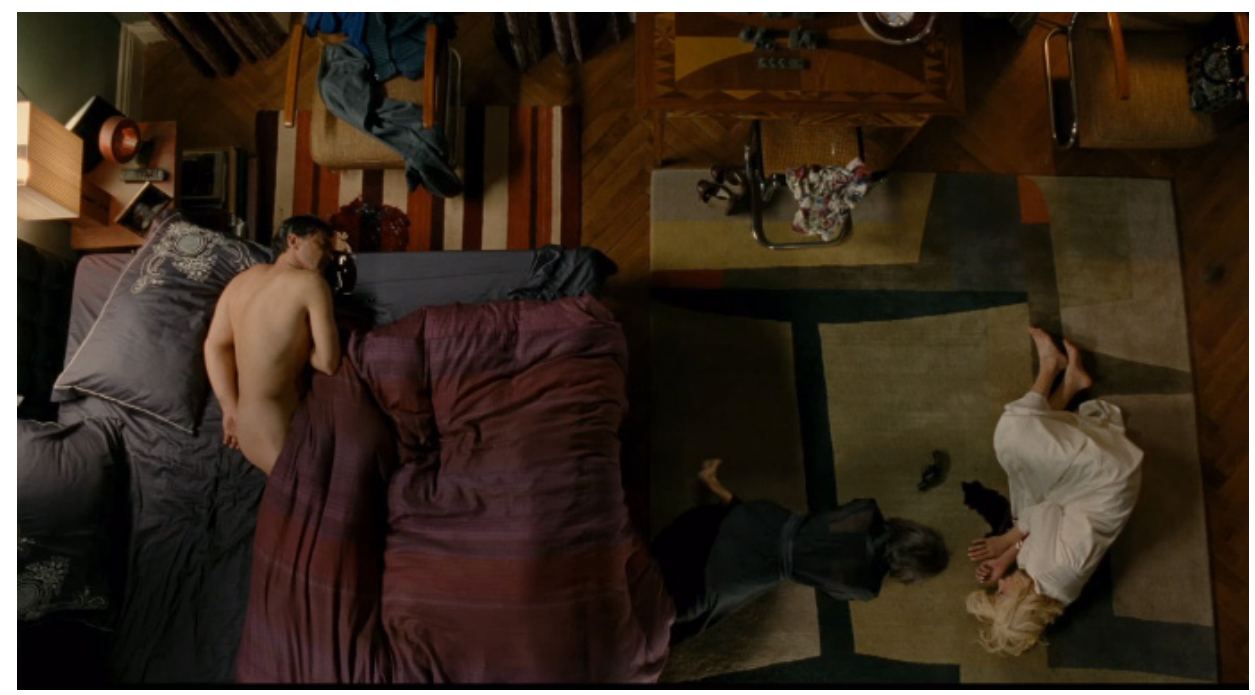

Figura 6. La piel que habito: plano cenital de Vera después de haber matado a Robert y Marilia

En esta escena, el plano cenital (figura 6) representa otra vez la posición del narrador omnisciente. El punto de vista, la posición del espectador se quiebra, la dialéctica de las miradas está ya destruida, lo que queda es la fluidez del cuerpo de Vera y de su mirada queer. De esta forma hacia el final de la cinta y a través de Vera, que es además un personaje transexual, la película La piel que habito tematiza una expansión de la noción de femenino que incluye también todas las experiencias de transición entre un género y el otro, y una sexualidad y la otra. La película va más allá de la dialéctica entre mirada masculina y mirada femenina, tematizando una noción de femineidad más amplia, que al mismo tiempo acoge las dos posibilidades sin coincidir con ninguna de las dos, rompiendo precisamente el esencialismo pernicioso que conlleva este binarismo, donde la mirada masculina se ve necesariamente como una mirada dominadora, y la mirada femenina necesariamente está conectada al deseo siempre incumplido de emancipación. Esto es porque siempre que haya una mirada masculina dominante y cosificadora habrá un cuerpo femenino cosificado y definido por su subalternidad. El personaje de Vera -Vera Cruz, se llama, como "cruce verdadero" para volver a la terminología de Paul B. Preciado- va más allá, desborda esta definición de lo femenino desafiando la polaridad misma entre mirada masculina y femenina, es decir, la misma gramática que en esta polaridad reproduce la división de género heterosexual y patriarcal. Rompe esta dialéctica entre las dos miradas precisamente haciéndolas coexistir simultáneamente en el mismo cuerpo. Ambas, y ninguna de las dos, per se.

\section{Conclusiones}

Para concluir, podemos decir que La piel que habito aborda, una vez más en la trayectoria cinematográfica de Pedro Almodóvar, el tema trans, que aquí aparece, de acuerdo con el final de la película, como una manera de permanecer en la transición 
o en la fluidez entre un género y otro, y así escapar a la rigidez identitaria. Para no esencializar el término "trans" como una categoría fija del vocabulario de género y sexualidad, podríamos hablar de "transitoriedad" en los términos definidos por la académica australiana Claire Colebrook (2015). Colebrook, extendiendo el trabajo de los filósofos franceses Jacques Derrida y Gilles Deleuze a este contexto, habla de maneras singulares de habitar transversalmente los géneros y de transitar entre géneros que parecen pertenecer fundamentalmente al ser humano en cuanto tal. El transitar aparecería así como una condición distintivamente humana. $\mathrm{O}$, más bien, como afirma Colebrook, podríamos decir que el transitar entre sexos y géneros es expresión de una transitividad más profunda y primordial que representa la condición fundante e ineliminable de lo que ha llegado a ser definido, a través de la historia del pensamiento occidental, como lo humano. Estas reflexiones nos permiten considerar, además, lo trans como algo que al mismo tiempo desborda tanto la categoría de género entendida como binaria, como la misma categoría de transgénero, entendida como institución igualmente identitaria de un posible tercer género que abarque todas las diferencias. Representando un perturbar y confundir cada tipo de borde, lo trans -de transitoriedad- es entonces lo que posee la fuerza de resistir toda normativización conceptual, a la vez enriqueciéndose de un potencial interseccional que abarca, atraviesa y quiebra toda identidad social y cultural de género, sexo, raza, etnicidad y clase. En estos términos, podemos entender el término queer, o cuir, según su trascripción fonética en español, como expresión de este mismo estado de transitoriedad y perturbación constante, que abarca todo lo que no se reconoce ni con la heteronormatividad del mundo heterosexual y cisgénero, ni con la agenda más tradicional de la misma comunidad LGBTQ+. El término queer, sin embargo, es un concepto amplio que abarca un gran espectro de fenómenos, no tiene un significado unívoco y, por lo tanto, ha sido muy debatido. Antes de la apropiación por las teorías de género y sexualidad norteamericanas a partir de los años 70, el término queer había ya estado circulando en la literatura inglesa por varios siglos con el sentido derogatorio de extraño, excéntrico e incluso "torcido". Solo con los movimientos de liberación de los años 70 se convirtió en un signo de orgullo y resistencia política (De Lauretis, 2015: nota 2). La expresión "teoría queer", además, apareció por primera vez en la academia estadounidense en los años 90, acuñada por la estudiosa italiana Teresa de Lauretis $(1991,2015)$. En esos años, para De Lauretis, esta expresión coincidía con la realización de un proyecto crítico cuyo objetivo era "deshacer o resistir a la homogeneización cultural y sexual en el ámbito académico" y al mismo tiempo cuestionar todas las formas de política identitaria o de la identidad (2015). De este cuestionamiento deriva también mi entendimiento del término queer y de lo que conlleva conceptualmente su transliteración fonética en el español cuir. Con la palabra cuir asistimos a una torsión geopolítica y a un desplazamiento epistémico de la teoría crítica queer estadounidense. La transliteración cuir, efectivamente, nace de la experiencia descolonial y transfeminista tanto española como latinoamericana, atenta a desmontar formas de marginalización y exclusión social conectadas a contextos culturales, sociales, políticos y étnicos diferentes del heteropatriarcado cisgénero blanco y de clase media denunciado por la academia norteamericana (Solás y Urko, 2016). Una vez más, el concepto de interseccionalidad demuestra su centralidad en este contexto para pensar género y sexualidad en el cruce con otras categorías identitarias como clase, raza y etnicidad, edad, capacidades físicas y competencias laborales (Creshaw, 1996). 
De esta forma, los términos queer/cuir representarían una manera para cuestionar la construcción de identidades como categorías fijas, tanto al interior del espectro LGBTQ+ como afuera de este, en el mundo cisgénero y heterosexual. A este respecto, articularían también una ética, es decir, una manera de ser del sujeto en relación con los demás, cuyo objetivo sería la progresiva transformación de la sociedad (Bernini, 2013). Llamo entonces mirada queer no solo a una técnica representativa -sea narrativa, cinematográfica o visual-, sino principalmente a la articulación de una epistemología atenta a las fisuras y a los puntos ciegos de los discursos dominantes, que permita pensar a contrapelo de estos discursos, y a la vez repensar lo femenino y lo masculino sin caer en categorías fijas y normativizantes de lo sexual. Se trataría de una teoría tanto antropológica, en la medida en que rompe con la reducción heteronormativa de lo humano, como epistemológica, en la medida en que cuestiona las lógicas de la percepción y la mirada, que, en sus representaciones, sea capaz de problematizar los discursos, los saberes y las epistemes que articulan nuestras experiencias de género y sexualidad. Todo esto, sin necesariamente abandonar la terminología de género en su totalidad y caer en el "éxtasis de un más allá del género", como dijo recientemente Nelly Richard, intelectual y crítica de arte entre las más destacadas en el panorama cultural latinoamericano contemporáneo en el encuentro titulado "Brechas de género y feminismos del siglo xxı" y organizado por la Universidad de Chile durante el Día Internacional de la Mujer, 8 de marzo de 2018. Pero sí es necesario, como afirma Richard, desactivar el disciplinamiento institucional del género, sospechar de sus clausuras monológicas (Richard, 2008) y deconstruir la separación de espacios y funciones en términos ideológico-sexuales, "darse cuenta de que la economía de la representación social se rige por un reparto discriminatorio" (Richard, 2001: 234). En este sentido, además, podríamos aplicar al análisis del lenguaje cinematográfico las observaciones de Richard con respecto de la pregunta acerca de si la escritura "tiene género" y por lo tanto por la posibilidad de hablar de escrituras "masculinas" y "femeninas". Richard sostiene que la escritura, y de la misma forma podemos hablar del texto o del lenguaje cinematográfico, "designa una travesía simbólica de las categorías de la identidad y la diferencia", las cuales son social y culturalmente construidas "por vía de la alteridad". Entonces, según Richard, "no podemos hablar, tan separadamente de escritura masculina y de escritura femenina ya que el lenguaje creativo [...] combina varias marcas de identidad en un proceso fluctuante de significación que desordena las pertenencias de género, ampliando y diversificando aquella zona fronteriza", esa zona que cruza confines y fronteras, que es tanto la escritura como el imaginario cinematográfico, en las que "se modulan los trazados simbólico-sexuales de subjetivación e identificación” (Richard, 2008: 17).

A partir de estas reflexiones, lo que se ha propuesto en este ensayo con el término mirada queer es la articulación tanto de una epistemología como, a la vez, de una manera de mirar y de articular representaciones, imaginarios y saberes, atenta a develar las fallas de los imaginarios que permean textos literarios o imágenes cinematográficas, opiniones públicas o instituciones estatales, los cuales aún dejan filtrar un inconsciente normativo y normalizador que, por ejemplo, todavía ve las transiciones de género como desviaciones o como resultado de eventos traumáticos, conductas o ambientes marginales y violentos. Así, leída bajo esta perspectiva, la película de Almodóvar establece precisamente, en mi opinión, la posibilidad crítica de introducir, pensar e incluso asumir lo que podemos llamar finalmente una mirada queer en el cine. Significativamente liberando a Vera de sus opresores, y dejándola ser en el 
mundo de afuera, Almodóvar nos da un mensaje de emancipación que a la vez representa un desafío ideológico a la dialéctica entre mirada masculina y mirada femenina en el cine. A nivel cinematográfico, lo hace interrumpiendo, por ejemplo, la cámara subjetiva, a través de un más neutral plano cenital y de las técnicas de superposición de imágenes, donde vemos muchas veces sobreponerse el cuerpo, los recuerdos y los deseos supuestamente "masculinos" de Vicente, con el cuerpo nuevo, el pensamiento presente y los deseos supuestamente "femeninos" de Vera. A nivel de narración, Almodóvar nos habla de ética y empatía, y nos da herramientas fundamentales para abrir la puerta hacia un futuro narrativo diferente donde lo trans y lo queer no estén asociados ni a un desarrollo narrativo necesariamente traumático y desviante, ni a un género cinematográfico específico o de nicho, categorizado como "cine gay" o "cine queer". ¿Cómo entender, entonces, una mirada en el cine que sea realmente capaz de cuestionar y deshacerse de la gramática binaria y opresiva de género? La respuesta no es tan sencilla ni definitiva, además de que no queremos caer en otro esencialismo de lo queer. La cuestión es, precisamente como decía Nelly Richard, que no podemos deshacernos totalmente de esta gramática binaria porque es esta gramática que aún gobierna las "reglas" de las sociedades en que vivimos, tanto representativas (narrativo-visuales) como políticas y sociales. Lo que sí podemos hacer, tal como sugiere La piel que habito, es modificar nuestra sensibilidad, flexibilizar e introducir una mayor fluidez en nuestra gramática de género. Sugerentemente para Vera, al final de la película, se abren las puertas de El Cigarral. Vuelve finalmente a la tienda de ropa de su madre, donde se presenta en su nuevo cuerpo, a la vez nombrándose y readueñándose de su propia identidad: soy Vicente, dice. Todos nuestros cuerpos transitan, Vera-Vicente están ahora listes para el mundo, es el mundo afuera, quizás, el que todavía no está listo para elles.

\section{Referencias bibliográficas}

Almodóvar, P. (1999) Todo sobre mi madre [cinta cinematrográfica]. España / Francia, El Deseo / Renn Productions / France 2 CinemaOn Screen Films.

Almodóvar, P. (2011) La piel que habito [cinta cinematrográfica]. España, El Deseo.

Almodóvar, P. (2012) La piel que habito. Barcelona, Anagrama.

Bernini, L. (2013) Apocalissi queer: elementi di teoria antisociale. Pisa, ETS.

Brechas de género y feminismos del siglo XXI (2018) Universidad de Chile. Disponible en: https://www.youtube.com/watch?v=jKF-HWhLOLA\&t=40s

Butler, J. (2006) Gender Trouble. Nueva York / Londres, Routledge.

Cabello Ruiz, M. T. (2014) "Intertextualidad en La piel que habito: Louise Bourgeois según Pedro Almodóvar" en Sesión No Numerada: Revista de Letras y Ficción Audiovisual, 4, pp. 34-46. Disponible en: https://dialnet.unirioja.es/ejemplar/363891

Colebrook, C. (2015) “What is it like to be a human?" en Transgender Studies Quarterly, 2, (2), pp. 227-243. Disponible en: https://read-dukeupress-edu.proxy.lib.umich.edu/tsq/issue/2/2

Crenshaw, K., N. Gotanda, G. Peller y K. Thomas (1996) Critical race theory: the key writings that formed the movement. Nueva York, The New Press.

D’Lugo, M. y K. M. Vernon (2013) A Companion to Pedro Almodóvar, Malden, MA, John Wiley \& Sons.

De Lauretis, T. (1991) "Queer theory. Lesbian and gay sexualities: An introduction” en Differences: A Journal of Feminist Cultural Studies, 3, (2), pp. iii-xviii. 
De Lauretis, T. (2015) “Género y teoría queer” en Mora, 21, (2). Disponible en: http://www. scielo.org.ar/scielo.php?script=sci_arttext\&pid=S1853-001X2015000200004\&lng=en\& tlng=en

Deleuze, G. y F. Guattari (2002) Mil mesetas. Capitalismo y esquizofrenia. Valencia, Pre-textos.

Foucault, M. (2017) Discurso y verdad: conferencias sobre el coraje de decirlo todo Grenoble, 1982 / Berkeley, 1983, Buenos Aires / México D. F., Siglo Veintiuno Editores.

Foucault, M. (2018) Vigilar y castigar: Nacimiento de la prisión. México D. F., Siglo Veintiuno Editores.

Franju, G. (1969) Los ojos sin rostro (1960) [cinta cinematrográfica]. Francia, Lux Film.

Gutiérrez-Albilla, J. D. (2018) Aesthetics, ethics and trauma and the cinema of Pedro Almodóvar. Edinburgo, Edinburgh University Press.

Halperin, D. M. (2003) "The normalization of queer theory" en Journal of Homosexuality, 45 (2-4), pp. 339-343. Disponible en: https://www.tandfonline.com/doi/abs/10.1300/ J082v45n02 17

Koyama, E. (2003) “The transfeminist manifesto" en Dicker, R C y A. Piepmeier, Catching a Wave: Reclaiming Feminism for the 21st Century. Boston, Northeastern University Press.

Jonquet, T. (2011) Tarántula. Barcelona, Ediciones B.

Jung, D. (2014) "Yuxtaposición artística en La piel que habito de Pedro Almodóvar: en torno a las obras de Tiziano, Louise Bourgeois, Guillermo Perez Villalta y Juan Gatti” en Neophilologus, (98), pp. 617-635. Disponible en: https://link.springer.com/ article/10.1007/s11061-014-9385-5

Laine, T. (2014) "Art as a guaranty of sanity: The skin I live in" en Alphaville: Journal of Film and Screen Media, 7, pp. 1-15. Disponible en: http://www.alphavillejournal.com/ Issue7/PDFs/ArticleLaine.pdf

Mayayo, P. (2002) Louise Bourgeois. Madrid, Nerea.

Mecacci, A. (2008) Introduzione a Andy Warhol. Roma, Laterza.

Nixon, M. (2005) Fantastic reality: Louise Bourgeois and a story of Modern art. Cambridge, MIT Press.

Mulvey, L. (2009) Visual and other pleasures. Basingstoke, Palgrave Macmillan.

Parés Pulido, M. (2014) "Intertextualidad en La piel que habito: Pintura, escultura y dibujo" en Fotocinema. Revista Cientifica de Cine y Fotografía, 9, pp. 325-360. Disponible en: http://www.revistas.uma.es/index.php/fotocinema/article/view/5973

Poyato Sánchez, P. (2015) "Programas iconográficos en La piel que habito (Almodóvar, 2011)" en Anales de Historia del Arte, 25, pp. 283-302. Disponible en: https://revistas. ucm.es/index.php/ANHA/article/view/50859

Preciado, P. B. (2019) Un Apartamento en Urano: Crónicas del cruce. Barcelona, Anagrama. Richard, N. (2001) "La problemática del feminismo en los años de la transición en Chile" en Estudios Latinoamericanos sobre Cultura y Transformaciones Sociales en Tiempos de Globalización, 2, Buenos Aires, Consejo Latinoamericano de Ciencias Sociales. Disponible en: http://biblioteca.clacso.edu.ar/clacso/gt/20100914035407/15richard.pdf

Richard, N. (2008) Feminismo, Género y Diferencia(s). Maipú, Palinodia.

Richard, N. (2018) Abismos temporales: feminismo, estéticas travestis y teoría queer. Santiago de Chile, Ediciones Metales Pesados.

Shapiro, J. (2008) "Transsexualism: Reflections on the persistence of gender and mutability of sex" en Robertson, J., Same-sex cultures and sexualities: An anthropological reader. Malden, MA, Blackwell Publishing.

Solà, M., y E. Urko (2016) Transfeminismos: epistemes, fricciones y flujos. México D. F., Encuadernaciones Huacal, MAreA NegrA Ediciones. 
The female gaze (2016) Master class (TIFF Industry Conference) por Jill Solway. Disponible en: https:/www.tiff.net/the-review/jill-soloway-conjures-the-goddess/

Thibaudeau, P. (2013) "El Cuerpo, la piel y la pantalla: Los territorios habitados por Pedro Almodóvar" en Fotocinema: Revista Cientifica de Cine y Fotografía, 7, pp. 192-208. Disponible en: http://www.revistafotocinema.com/index.php?journal=fotocinema\&page $=$ article\&op=viewFile\&path $\% 5 \mathrm{~B} \% 5 \mathrm{D}=198 \&$ path $\% 5 \mathrm{~B} \% 5 \mathrm{D}=133$ 